\title{
Optimal Location of Distributed Generation Sources and Capacitance of Distribution Network to Reduce Losses, Improve Voltage Profile, and Minimizing the Costs Using Genetic and Harmonic Search Algorithm
}

\author{
Mahdi Mansouri \\ MSc of Executive Management, Marketing \\ Strategy, Islamic Azad University \\ Ahar, East Azarbaijan, Iran
}

\author{
Hosein Gholizadeh \\ Dept. of Electrical Engineering, Islamic Azad \\ University Central Tehran Branch College \\ Tehran, Iran
}

\begin{abstract}
Reducing losses and improving the voltage profile have been the main objectives of electrical power system designers. One of the suggested solutions for achieving these goals is the use of parallel capacitors and distributed generation sources in distribution systems. A location that is optimized for DG installation may not be the best place to minimize losses in improving the system voltage profile. In this paper, determining the optimal location of the dispersed generation unit and the capacitive bank with the goal of optimizing a target function, including losses, improving the voltage profile, and the cost of investment in capacitors and dispersed production. In this paper, IEEE standard 33 buses is considered for simulation, and the results are obtained by using genetic and harmonic search algorithm indicate that DG optimization and capacitor with a target function in which the loss reduction and improvement of the voltage profile is considered to reduce costs, reduce losses, and improve the voltage profile, which are remarkable improvements.
\end{abstract}

Keywords: Optimal Placement; Distributed Generation; Genetic Algorithm; Voltage Profile; Harmonic Search Algorithm;

\section{INTRODUCTION}

Renewable energies are becoming more common as because of increasing electricity demand. Optimal placement of Distributed generation (DG) in power systems has high importance for improving voltage stability, reducing loses, and minimizing the costs [1].

Reducing losses and improving the voltage profile is one of the most important issues in the power industry. There is also a large share of energy losses in the distribution sector, which is equivalent to about $75 \%$ of the data in this area. Therefore, consideration of issues such as location, capacitance, and renetworking are essential. Distributed generation generally refers to low power generation sources, typically between KW1 to MW50 that are located near the consumer location or connected to the distribution network [2-4]. One of the important issues in distributed generation studies is the problem of placement and determination of their capacity. The disposition of the dispersed production on the power transmission and the number of losses is significant $[5,6]$. Due to the network's electrical parameters, load distribution equations, and the constraints on the use of distributed generation sources, the problem of displacement will have some characteristics that, from an optimization perspective, are some of these characteristics:

- $\quad$ The resulting equations are nonlinear [7]

- The variable of a state that can predict the existence or absence of a source is a discrete variable. The variable of a state that can predict the existence or absence of a Distributed generation source in a busbar is a discrete variable [8].
- Since there is virtually no capacity for installation, and the source cannot be dispersed in each shin, the target function is a discontinuous function [9].

- For real networks, the problem becomes an issue for a very large dimensional problem [10].

Capacitors are used as one of the most economical methods for increasing the electrical power quality so that the optimal location of this element has a significant effect on the transmission power, the loss of lines, the voltage profile, and the reliability of the network [11-14]. Static voltage stability of grid in south-east Iran power system has been conducted in [15-17]. Extended continuation power flow is used to get more accurate results in this system.

The use of parallel capacitors and distributed generation in the distribution system to increase the electrical power quality and reduce the cost of the system in the system has always been one of the important issues for engineers [18]. The installation of parallel capacitors and distributed generation generators will have many benefits for manufacturers and consumers of electrical energy, which will be referred to later in this chapter. Maximum access to the above benefits depends on how they are installed in the distribution system since their optimal placement has a great influence on the power transmission, the number of line losses, the voltage profile, and the reliability of the network. On the other hand, improper placement of distributed generation generators in the system will cause disadvantages such as increasing losses, reducing voltage and increasing costs [19].

Therefore, the problem of determining the location and optimal capacity size of capacitor banks and distributed generation should be addressed, which is referred to as the 
problem of optimal placement of capacitors and distributed generation. Hence, various methods have been proposed by researchers in different scientific institutions for the last decades [20]. In this chapter, first, a brief summary of capacitors and distributed generation are described. Then, a brief overview of the above methods and the work done so far is discussed.

As you can see, two of the objective profit target functions and the voltage profile indicator for this issue are considered. In most articles, a function is called the cost function using the following formula.

$$
F=\sum_{i=1}^{n b} k_{p} \cdot P_{l o s s}^{i}+\sum_{j=1}^{n c} k_{c} \cdot Q_{c}^{j}
$$

In which, $P_{\text {loss }}^{i}$ is loss in section $\mathrm{i}$, nb is the numbers of sections in the network, $Q_{c}^{j}$ is the value for capacitance in section $\mathrm{j}$, nc is the numbers of capacitors, $\mathrm{k}_{\mathrm{p}}$ is the expense of power per $\mathrm{kW}$, and $\mathrm{k}_{\mathrm{c}}$ is the cost of capacitor per KVAR. Casualties in the distribution network include two parts of power and energy. The power losses are related to peak loading and the energy losses associated with loading over a period (one year), which can be calculated using the loss factor of peak losses. Kp is the total cost of power and energy losses per kw of peak losses. After the capacitance, the gain from the capacitance in the network can also be calculated by using the following formula, which is presented as the main objective function in the capacitance.

$$
S=k_{e} \times 8760 \times \operatorname{LSF}\left(P_{l}-P_{l}^{c}\right)-\sum_{i=1}^{n c} k_{c} \cdot Q_{c i}
$$

In which, $\mathrm{k}_{\mathrm{e}}$ is the cost of energy losses, LSF is loss factor, $\mathrm{P}_{1}$ is courier loss before capacitance, $P_{l}^{c}$ is Peak losses are after capacitance. Table 3 also shows information about this objective function, as well as the profit function. The exploitation of distribution networks in normal conditions due to appropriate protection coordination, limiting the network interface level and the problems of exploiting interconnected networks, are often carried out radially, and the numerous disconnect switches available on the network play a significant role in Network structure management functions to achieve optimal form. Replacing or changing the arrangement in the distribution network, changing the arrangement of feeders, opening and closing switches (power switches, removable and non-removable actuators under load, etc.) to change the topology of the network.

\section{OBJECTIVE FUNCTION}

\subsection{Loss}

The casualty has various causes, part of which is the main part of it, is part of the essence of the network. Because everywhere there is a network of conductors, casualties are inevitable due to the flow of conductors. The first objective function is the active loss of the feeders of the distribution network, which is expressed as:

$$
\min P_{\text {loss }}=\sum_{i=1}^{n_{p}} r_{i} \frac{P_{i}^{2}+Q_{i}^{2}}{V_{i}^{2}}
$$

In which, $n_{p}$ is a total number of network branches, $r_{i}$ is the resistance of branch $I, Q_{i}$ is the reactive power of branch $i, P_{i}$ is the active power of branch $\mathrm{I}$, and $\mathrm{V}_{\mathrm{i}}$ is the voltage of branch i.

\subsection{Voltage}

From the perspective of consumers, having a voltage in the limit is one of the important factors in the quality of electricity. Radial networks at the end of their own usually suffer from a weak voltage. Replacing with the change in the flow path, it can modify the voltage profile to a certain extent, which is almost synonymous with loss reduction [21]. The next target function is related to the voltage profile indicator, the mathematical formulation of which is expressed as follows:

$$
\begin{aligned}
& \min V_{s}=\sqrt{\frac{1}{n} \sum_{i=1}^{n_{b}}\left(V_{i}-V_{p}\right)^{2}} \\
& V_{p}=\frac{1}{n} \times \sum_{i=1}^{n_{b}} V_{i}
\end{aligned}
$$

In which, $\mathrm{V}_{\mathrm{s}}$ is voltage index, $\mathrm{V}_{\mathrm{i}}$, the voltage of branch $\mathrm{i}, \mathrm{n}_{\mathrm{b}}$ is the number of network nodes, and $V_{p}$ is Average node voltage.

\section{CONSTRAINTS}

In all optimization steps, the following constraints should be considered [22-24]:

1. The radial constraint of the grid: In all the matching arrangements, the grid must always maintain its radial structure.

2. Node Voltage Limit Constraint: $V_{i \min } \leq V_{i} \leq V_{i \max }$

3. Limitation of the flow of branches: $I_{n}\left\langle I_{n \text { max }}\right.$

4. All nodes are always energized: All network nodes in the arrays obtained from the algorithm should always be light and not isolated in the network.

\section{OPTIMIZATION METHODS}

\subsection{Genetic Algorithm}

Genetic algorithms are based on chromosomes and their natural evolution. In this method, contrary to the analytical methods, try and error, instead of working on an optimal answer, they work on several answers that they call "populations". As a result, the problem space is searched more effectively. Also, search and evolutionary operations take place on the coded state of the answers, which is generally binary coding. A specific feature of the way genetic algorithms is based on solving optimization problems is that these methods have high efficiency in the absence of specific information about the problem or the need for specific conditions of the response space such as uniformity, convexity, and single-valuedness [25, 26].

Another important feature of these algorithms in terms of computational programming is that each member of the population does not respond to other members and 
independently evolves. Therefore, in solving complex and heavy problems, parallel processors and the robust controller can be used to quickly solve the problem [27].

In the case of the economic distribution of the load, given that we have $\mathrm{N}$ units of production, we consider $\mathrm{N}-1$ unit (variable) because, with the capability of producing $\mathrm{N}-1$ units, the production capacity of unit N, which is also Pref We can call it the form (6). Generally, Pref is divided into units whose production range (ie, Pmin-Pmax) is higher than other units.

$P_{\text {ref }}=P_{L}-\sum_{i=1}^{N-1} P_{1}$

In this paper, binary coding is used to apply the genetic algorithm to solve the problem of economic distribution of charge, and each chromosome, resulting from the combining of the encoded string of numerical values of $\mathrm{N}-1$ varies. In the above problem, the length of the encoded string of the variable $\mathrm{i}$ is the smallest integer corresponding to (7).

$$
2^{m-1}\left\langle\left(P_{i, \max }-P_{i, \min }\right) \times 10^{i} \leq 2^{m}-1\right.
$$

In which, $m_{i}$ is The length of the $i$-th encoded variable, $P_{i, \max }$ is produced power, $\mathrm{P}_{\mathrm{i} \text {,min }}$ is the minimum produced power, and I is the number of digits after decimals. After joining the encoded fields of variables, the chromosome contains the coded values of all the variables. Therefore, the length of the chromosomes of the algorithm can be determined from equation (8).

$$
L=\sum_{i=1}^{N-1} m_{i}
$$

Obviously, with the increase in the number of chromosome production units of the algorithm, the amount of memory in the system increases linearly. Also, to return the chromosome to true values of the problem variables, first each chromosome is divided into the corresponding coding sequences, and then we use equation (9).

$$
P_{1}=P_{i, \min }+\operatorname{decimal}(\text { substring }) \times \frac{P_{i, \max }-p_{i, \min }}{2^{m}-1} \text { (9) }
$$

The initial population of the genetic algorithm is randomly formed, and then the following evolutionary processes occur on a population and a new generation emerges:

- Roulette cycle: In this process, population chromosomes are selected with a probability proportional to the chromosomal fitness (value of the target function) [28]. In this process, chromosomes may be selected more than once (a strong chromosome) or chromosomes never to be selected (weak chromosome) [29].

- Cross-over: In this process, two parent chromosomes are produced by two child chromosomes [30]. The simplest algorithm for this process is the discontinuous cutting algorithm. This process takes place with the probability of a $\mathrm{p}_{\mathrm{c}}$ population [31].

- Mutation: During this process, several genes (bits) of chromosomes of the population change from one to zero, or vice versa, from zero to one [32]. This process is applied to the population with a small probability of $\mathrm{p}_{\mathrm{m}}$ [33].
In the first process, chromosomes of the population converge to the superior chromosomes (or chromosomes). In the second process, the child's chromosomes create the properties of their parents and direct the algorithm to the optimum point. To move faster towards the optimal point, it's best to always have one parent, the best chromosome of the generation. In the third process, it is possible to enter chromosomes whose probability of entry into the algorithm is very low and may even be the optimal solution to the problem. The probability of this process should be low so that the algorithm does not find a random process. As it is obvious, the coupling process causes the convergence and the mutation process causes the divergence of the algorithm. Therefore, for the fastest convergence, one can estimate the overall fitness of a generation in each generation and correct the probabilities of $\mathrm{Pc}$ and $\mathrm{Pm}$ for future generations. An important point to note is that there may be a chromosomal algorithm that does not belong to the response space. In such a case, in the case of the economic distribution of time, there is no time for which Pref does not fall within its scope of production, namely:

$$
P_{\text {ref }} \notin\left|P_{\min , r e f}, P_{\max , r e f}\right|
$$

In this case, we must remove the chromosome and replace the other chromosome. This process is corrected as linear. The genetic algorithm cycle is presented in the flowchart of figure 1.

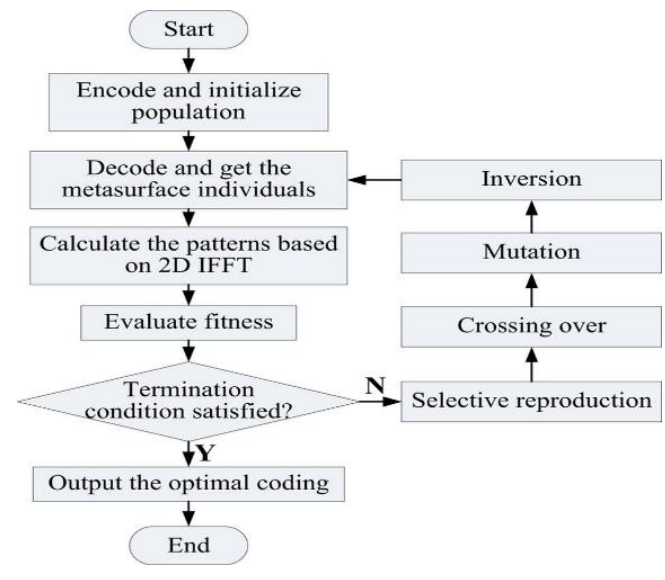

Figure 1. Genetic Algorithm flowchart

\subsection{Harmonic Search Algorithm}

Nowadays, with increasing issues and the importance of speeding up the response and failure to respond to classical methods, the search algorithms of the full-scale problem space are welcome. In the meantime, the use of hyper surfing (intuitive) search algorithms also has an inherited growth algorithm, ants colony algorithm, and so on [34]. Due to the unique features of the Harmonic Search Algorithm (HSA), this search method has been used.

Characteristics of the Harmony Search Algorithm are:

- There is no need to search for the initial value, and the problem is not trapped in the optimal local response [35].

- Instead of searching for a derivative of random search, an optimal answer is used [36].

- In contrast to derivative-based optimization methods, in addition to continuous variables, it has the ability to work with discrete variables [37]. 
- Also, the Harmonic Search algorithm uses some of the features of other meta-innovative algorithms, such as preserving previous vectors of a similar taboo search algorithm (TS), providing harmonic memory from the start to the end of simulated cooking (SA) and evaluating multiple Vector at the same time as the inheritance algorithm. But compared to them, they have less mathematical prerequisites and the ability to solve various engineering optimizations. The Harmonic Search algorithm creates a new answer after considering all the answers. While the inheritance algorithm considers only two parent polynomials, this flexibility increases the search algorithm's harmony and results in the optimal answer.

The steps in which the algorithm searches for harmonics for optimization is that in the first step, initialization of the problem parameters and algorithm is performed; in the second and third steps, the initialization of the first harmonic memory (HM) and the creation of a new harmony respectively Harmony memory is performed; in the next steps, updating the harmonic memory and checking the stop condition is done. The parameters of the Harmony Search Algorithm, which can have different values in each issue. The intended settings for the Harmony Search Algorithm include the size of the Harmonic Memory (HMS), the speed of the Harmonic Memory Check (HMCR), the Bandwidth Parameter Parameterization (Bw), the Manufacturing Numbers (NI) in Table 2 [38-44].

Table 1. Harmonic search algorithm parameters

\begin{tabular}{|c|c|}
\hline Parameter & \multicolumn{1}{|c}{} \\
\hline HMS & 10 \\
\hline HMCR & $0 / 85$ \\
\hline PAR & $0 / 3$ \\
\hline
\end{tabular}

The flowchart and algorithm process are shown in Figure 2.

\section{SYSTEM'S MODEL}

In this paper, six scenarios for solving the problem of repositioning and capacitance (four capacitors with a capacity of 50kvar) and distributed generation sources have been investigated to reduce losses and improve the voltage profile of an IEEE 33base network. Information about the distributed source is shown with the specifications specified in Table (2). Specifications for the objective function. The cost of loss and profit from the condensation are shown in Table (3).

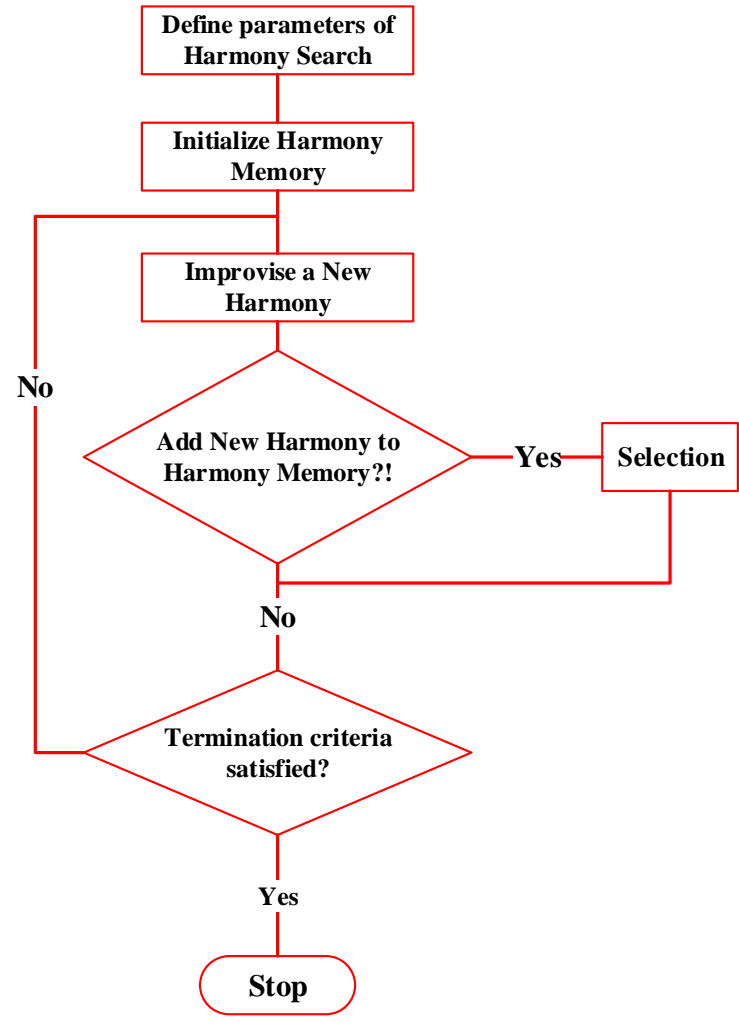

Figure 2. The flowchart of Harmonic Search Algorithm

Table 2. The initial location of the distributed production resources and their size

\begin{tabular}{|c|c|}
\hline \multicolumn{2}{|c|}{$\begin{array}{c}\text { 33-Bus Installation node } \\
\text { and capacity of DG }\end{array}$} \\
\hline Node & Capacity(kw/p.f) \\
\hline 3 & $50 / 0.8$ \\
\hline 6 & $100 / 0.9$ \\
\hline 24 & $200 / 0.9$ \\
\hline 29 & $100 / 1$ \\
\hline
\end{tabular}

Table 3. Information about the objective function of the cost of loss and profit

\begin{tabular}{|c|c|}
\hline Parameter & Value \\
\hline$k_{p}(\$ / \mathrm{kw})$ & 120 \\
\hline$k_{c}(\$ / \mathrm{kvar})$ & 5 \\
\hline$k_{e}(\$ / \mathrm{kwh})$ & 0.3 \\
\hline$L S F$ & 0.554 \\
\hline
\end{tabular}




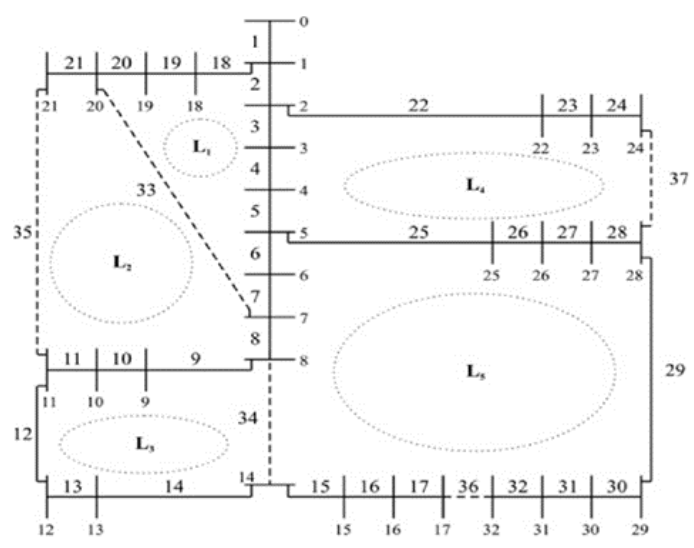

Figure 3. IEEE 33-buses system

\section{SIMULATION RESULTS}

In the first scenario, the network openness was researched with the assumption that the location of distributed sources of production was constant (Table 2), the active network losses in the presence and absence of distributed generation sources.

Table 4. The 33-bus network active casualties without the presence of distributed generation sources

\begin{tabular}{|c|c|c|c|}
\cline { 2 - 4 } \multicolumn{1}{c|}{} & open switch & $\begin{array}{c}\text { Ploss } \\
(\mathbf{K W})\end{array}$ & $\begin{array}{c}\text { Reduction } \\
(\%)\end{array}$ \\
\hline initial & $\mathrm{s} 33, \mathrm{~s} 34, \mathrm{~s} 35, \mathrm{~s} 36, \mathrm{~s} 37$ & 202.5 & - \\
\hline$G A$ & $\mathrm{~s} 7, \mathrm{~s} 9, \mathrm{~s} 14, \mathrm{~s} 32, \mathrm{~s} 37$ & 139.5 & 31.11 \\
\hline$H S$ & $\mathrm{~s} 7, \mathrm{~s} 9, \mathrm{~s} 14, \mathrm{~s} 28, \mathrm{~s} 32$ & 139.9 & 30.91 \\
\hline
\end{tabular}

Table 5. The 33-bus network active casualties in the presence of distributed generation sources

\begin{tabular}{|c|c|c|c|}
\cline { 2 - 4 } \multicolumn{1}{c|}{} & open switch & $\begin{array}{c}\text { Ploss } \\
(\mathbf{K W})\end{array}$ & $\begin{array}{c}\text { Reduction } \\
(\%)\end{array}$ \\
\hline initial & $\mathrm{s} 33, \mathrm{~s} 34, \mathrm{~s} 35, \mathrm{~s} 36, \mathrm{~s} 37$ & 169.75 & - \\
\hline$G A$ & $\mathrm{~s} 7, \mathrm{~s} 9, \mathrm{~s} 14, \mathrm{~s} 28, \mathrm{~s} 32$ & 115.72 & 31.82 \\
\hline$H S$ & $\mathrm{~s} 7, \mathrm{~s} 10, \mathrm{~s} 14, \mathrm{~s} 28, \mathrm{~s} 32$ & 116.44 & 31.41 \\
\hline
\end{tabular}

The presence of these resources in the same initial arrangement has reduced losses from $202.5 \mathrm{kV}$ to $169.75 \mathrm{~kW}$. But after applying the rearrangement in both of these ways, losses from the original arrangement were significantly reduced by two algorithms. Network losses have been reduced by 31.82 percent using a genetic algorithm and also with Harmonic Search Algorithm, with a very near-optimal reduction of 31.41 percent. In the case comparison case, the casualties achieved for the optimal arrangement of genetic algorithms in the absence of distributed sources of resources have reached 139.5 to 115.72 in the presence of these resources. And the impact of the presence of these resources is quite visible.

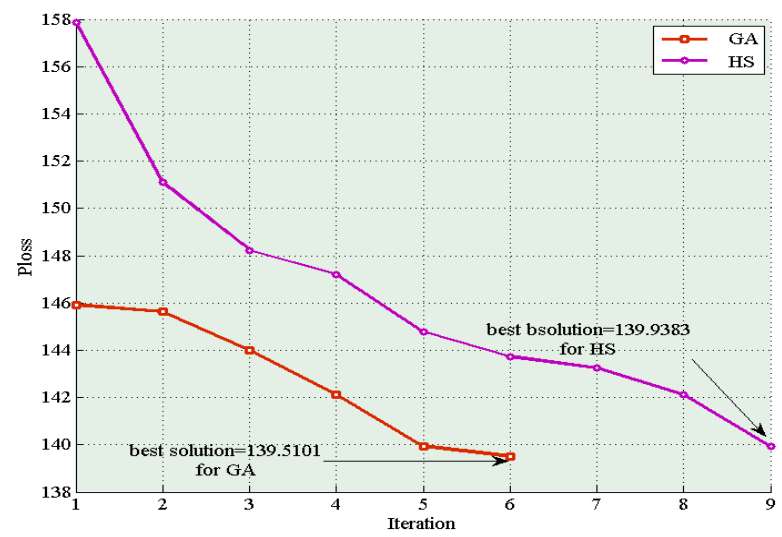

Figure 4. Comparison of the convergence diagrams of 2 algorithms for the 33 buses network without DG presence

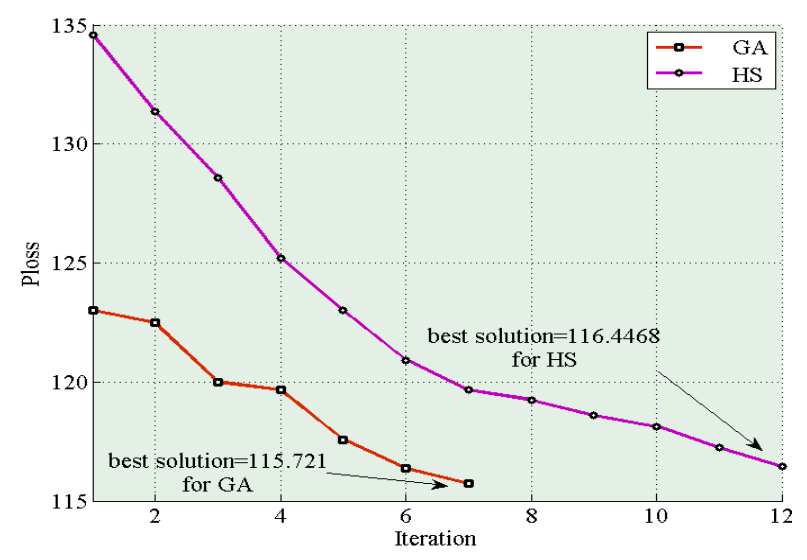

Figure 5. Comparison of the convergence graphs of 2 algorithms for the 33 mesh buses with DG presence

In the second scenario, the grid opt-out option, with the assumption of the constant location of the distributed generation sources (as in Table 2), indicates the network voltage profile in the presence and absence of these resources.

Table 6. 33-Bass Network Voltage Profile Indicator without Distributed Production Resources

\begin{tabular}{|c|c|c|c|}
\cline { 2 - 4 } \multicolumn{1}{c|}{} & open switch & $\begin{array}{c}\text { Voltage } \\
\text { profile } \\
\text { index }\end{array}$ & Reduction \\
\hline initial & $\mathrm{s} 33, \mathrm{\%} 34, \mathrm{~s} 35, \mathrm{~s} 36, \mathrm{~s} 37$ & 0.02984 & - \\
\hline$G A$ & $\mathrm{~s} 9, \mathrm{~s} 14, \mathrm{~s} 28, \mathrm{~s} 32, \mathrm{~s} 33$ & 0.01630 & 45.37 \\
\hline$H S$ & $\mathrm{~s} 7, \mathrm{~s} 9, \mathrm{~s} 14, \mathrm{~s} 28, \mathrm{~s} 32$ & 0.01637 & 45.14 \\
\hline
\end{tabular}


Table 7. 33-Bass network voltage profile index in the presence of distributed generation sources

\begin{tabular}{|c|c|c|c|}
\cline { 2 - 4 } \multicolumn{1}{c|}{} & open switch & $\begin{array}{c}\text { Voltage } \\
\text { profile } \\
\text { index }\end{array}$ & $\begin{array}{c}\text { Reduction } \\
(\%)\end{array}$ \\
\hline initial & $\mathrm{s} 33, \mathrm{~s} 34, \mathrm{~s} 35, \mathrm{~s} 36, \mathrm{~s} 37$ & 0.02803 & - \\
\hline$G A$ & $\mathrm{~s} 9, \mathrm{~s} 14, \mathrm{~s} 28, \mathrm{~s} 33, \mathrm{~s} 36$ & 0.01525 & 45.59 \\
\hline$H S$ & $\mathrm{~s} 7, \mathrm{~s} 9, \mathrm{~s} 14, \mathrm{~s} 28, \mathrm{~s} 36$ & 0.01573 & 43.88 \\
\hline
\end{tabular}

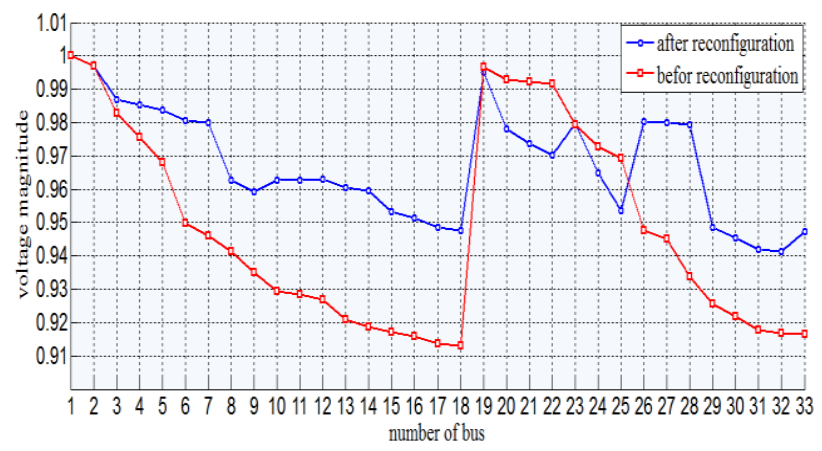

Figure 6. Comparison of network voltage profile of 33 bass before and after rearrangement in the absence of DG

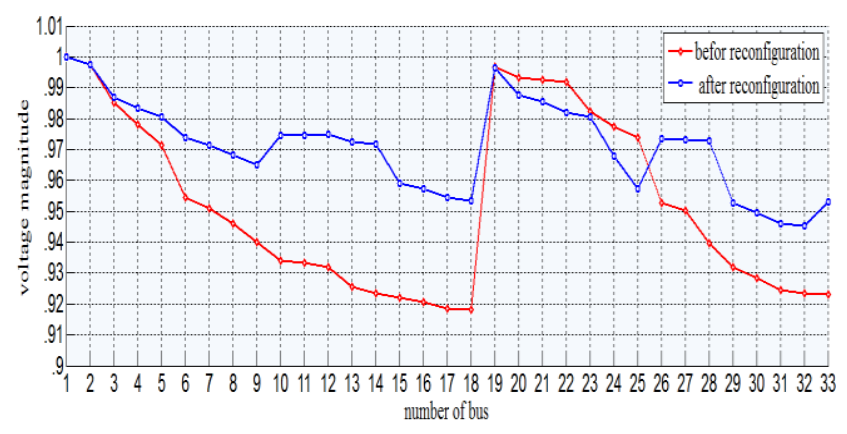

Figure 7. Comparison of network voltage profile of 33 bass before and after rearrangement in the presence of DG

In both cases, the voltage range of most network nodes has increased after rearrangement and closer to 1 per unit, and the whole graph is smoother than before the rearrangement. Second, the voltage range of most nodes has increased significantly compared to the initial arrangement before, after the presence of distributed generation sources, and the comparison of the optimal arrangement before and after the presence of distributed generation sources.

In the third scenario, the effect of the optimal location of distributed generation sources on the reduction of active network losses in the presence of these resources has been studied.
Table 8. The 33-bass network active losses in the DGs primary location and in DGs optimal locations

\begin{tabular}{|c|c|c|c|}
\cline { 2 - 4 } \multicolumn{1}{c|}{} & The location of DGs & $\begin{array}{c}\text { Ploss } \\
\mathbf{( k W )}\end{array}$ & $\begin{array}{c}\text { Reduction } \\
\mathbf{( \% )}\end{array}$ \\
\hline Initial & $\begin{array}{c}\text { (DG1=3),(DG2=6), } \\
(\mathrm{DG} 3=24),(\mathrm{DG} 4=29)\end{array}$ & 169.76 & - \\
\hline GA & $\begin{array}{c}\text { (DG1=33),(DG2=18), } \\
(\mathrm{DG} 3=32),(\mathrm{DG} 4=17)\end{array}$ & 135.57 & 20.14 \\
\hline$H S$ & $\begin{array}{c}\text { (DG1=33),(DG2=18), } \\
(\mathrm{DG} 3=32),(\mathrm{DG} 4=17)\end{array}$ & 135.57 & 20.14 \\
\hline
\end{tabular}

As you can see, the active power losses in the initial arrangement with the placement of resources in non-optimal locations are $169.66 \mathrm{~kW}$. After applying the optimal location on the network, the genetic algorithm reduces the cascade from $169.76 \mathrm{~kW}$ to $135.51 \mathrm{~kW}$, decreasing by $20.14 \%$ compared to the initial state. The optimum arrangement with the location of dispersed 1,2, 3 and 4 generation sources were obtained at places 33, 18, 32 and 17, respectively. The Harmony Search algorithm also has the same function. In the fourth scenario, with the optimal location of dispersed sources of production, the analysis of the voltage profile indicator in the presence of these resources is discussed.

Table 9. The 33-bass network voltage profile index in the DGs primary location and in the DGs optimal location

\begin{tabular}{|c|c|c|c|}
\cline { 2 - 4 } \multicolumn{1}{c|}{} & The location of DGs & $\begin{array}{c}\text { Profile } \\
\text { Voltage } \\
\text { Index }\end{array}$ & $\begin{array}{c}\text { Reduction } \\
(\boldsymbol{\%})\end{array}$ \\
\hline initial & $\begin{array}{c}\text { (DG1=3),(DG2=6), } \\
(\mathrm{DG} 3=24),(\mathrm{DG} 4=29)\end{array}$ & 0.0280 & - \\
\hline$H S$ & $\begin{array}{c}(\mathrm{DG} 1=32),(\mathrm{DG}=17), \\
(\mathrm{DG} 3=18),(\mathrm{DG} 4=16)\end{array}$ & 0.021656 & 22.65 \\
\hline & $\begin{array}{c}\text { (DG1=16),(DG2=17), } \\
(\mathrm{DG} 3=18),(\mathrm{DG} 4=33)\end{array}$ & 0.021658 & 22.65 \\
\hline
\end{tabular}

After optimal positioning on this network, the voltage profile index is significantly improved compared to the initial state. The optimum arrangement with the distribution of dispersed $1,2,3$ and 4 production sources was obtained at places 32,17 , 18 and 16, respectively. The Harmonic Search algorithm also has a roughly similar function. In the fifth scenario, the active losses and annual net profit of the studied network are investigated after optimal location of the capacitor. 
Table 10. The active casualties and the annual profit of the 33 Bass Network after being delivered to the optimal location

\begin{tabular}{|c|c|c|c|}
\cline { 2 - 4 } \multicolumn{1}{c|}{} & $\begin{array}{c}\text { The location of } \\
\text { Capacitors }\end{array}$ & Ploss & Profit \\
\hline initial & - & 202.5 & (\$) \\
\hline$G A$ & $\begin{array}{c}(\mathrm{C} 1=30),(\mathrm{C} 2=31), \\
(\mathrm{C} 3=32),(\mathrm{C} 4=33)\end{array}$ & 184.3401 & 25255.745 \\
\hline$H S$ & $\begin{array}{l}(\mathrm{C} 1=18),(\mathrm{C} 2=31), \\
(\mathrm{C} 3=32),(\mathrm{C} 4=33)\end{array}$ & 184.6836 & 24933.2407 \\
\hline
\end{tabular}

After applying the optimum location of the capacitor on the network, the genetic algorithm reduces the losses from 202.5 $\mathrm{kW}$ to $184.3401 \mathrm{~kW}$, yielding $\$ 25,255.745$. The optimum arrangement with capacitors $1,2,3$, and 4 was arranged in places 30, 31, 32 and 33, respectively. The Harmonic Search algorithm has also been shown to function. In the sixth scenario, the voltage profile and the annual profit of the studied network after the optimal location of the capacitor are investigated.

Table 11. Voltage Profile Profit and 33-Bass Annual Network Profit After Optimization

\begin{tabular}{|c|c|c|c|}
\cline { 2 - 4 } \multicolumn{1}{c|}{} & $\begin{array}{c}\text { The location of } \\
\text { Capacitors }\end{array}$ & $\begin{array}{c}\text { Voltage } \\
\text { Profile } \\
\text { Index } \\
(\mathbf{k W})\end{array}$ & Profit \\
\hline initial & - & 0.02984 & - \\
\hline$G A$ & $\begin{array}{c}(\mathrm{C} 1=16),(\mathrm{C} 2=18), \\
(\mathrm{C} 3=15),(\mathrm{C} 4=17)\end{array}$ & 0.027611 & 293776.1576 \\
\hline$H S$ & $\begin{array}{c}(\mathrm{C} 1=16),(\mathrm{C} 2=17), \\
(\mathrm{C} 3=14),(\mathrm{C} 4=18)\end{array}$ & 0.027631 & 293776.1282 \\
\hline
\end{tabular}

After optimizing the location on this network, the voltage profile index is significantly improved compared to the initial state. The optimal arrangement with capacitors 1, 2, 3, and 4 was arranged in places $16,17,18$ and 15 , respectively. The Harmonic Search algorithm also has a roughly similar function.

\section{CONCLUSION}

Genetic algorithm is very suitable for solving this problem due to easy compatibility with discrete variables and having an operator to escape local optimizations. In the case of Harmonic Search Algorithm, it is necessary to spend more time adjusting because the proper adjustment of its parameters is of great importance. Therefore, the incorrect adjustment of these parameters leads to the algorithm's capture in local optimizations or the failure to find the correct answer. Also, the algorithm of Harmonic Search, because it makes the answers in the whole process of performing the variable algorithm into a variable, so an unacceptable response is not generated, and this property has a very high-speed algorithm that if other parameters are set correctly It is very suitable for large networks. While two genetic algorithms produce the answers, they examine the constraints after production. Instead, genetic algorithms, because of their high public search capability, and due to the operator's ability to escape from the local optimization, consider more space at the same time and are less likely to be caught up in local optimizations. But initializing the initial population in the genetic algorithm is very important, and at the time of the convergence of the algorithm and finding the optimal solution is effective. It was also found that the presence of distributed generation resources could be effective in reducing the losses and increasing the voltage range of the various points of the network that dropped.

\section{REFERENCES}

[1] K. Yousefpour, "Placement of Dispersed Generation with the Purpose of Losses Reduction and Voltage Profile Improvement in Distribution Networks Using Particle Swarm Optimization Algorithm," Journal of World's Electrical Engineering and Technology, vol. 2322, p. 5114, 2014.

[2] N. Fahimi, M. R. Chalaki, M. A. Baferani, M. R. Tajik, and A. A. Shayegani, "Investigating the failures of defected silicon rubber insulators in salt-fog chamber," in Texas Power and Energy Conference (TPEC), 2018 IEEE, 2018, pp. 1-6.

[3] M. Rostaghi-Chalaki, A. Shayegani-Akmal, and H. Mohseni, "HARMONIC ANALYSIS OF LEAKAGE CURRENT OF SILICON RUBBER INSULATORS IN CLEAN-FOG AND SALT-FOG," in 18th International Symposium on High Voltage Engineering, 2013, pp. 1684 1688.

[4] M. Rostaghi-Chalaki, A. Shayegani-Akmal, and H. Mohseni, "A STUDY ON THE RELATION BETWEEN LEAKAGE CURRENT AND SPECIFIC CREEPAGE DISTANCE," in 18th International Symposium on High Voltage Engineering (ISH 2013), 2013, pp. 1629-1623.

[5] A. Hamedi and M. Ketabdar, "Energy Loss Estimation and Flow Simulation in the skimming flow Regime of Stepped Spillways with Inclined Steps and End Sill: A Numerical Model," International Journal of Science and Engineering Applications, vol. 5, pp. 399-407, 2016.

[6] A. Hamedi, "Advanced Characterization of Hydraulic Structures for Flow Regime Control: Experimental Developement," 2017.

[7] P. Dehghanian, S. Aslan, and P. Dehghanian, "Quantifying power system resilience improvement using network reconfiguration," in IEEE 60th International Midwest Symposium on Circuits and Systems (MWSCAS), 2017, pp. 1-4.

[8] H. Pourgharibshahi, M. Abdolzadeh, and R. Fadaeinedjad, "Verification of computational optimum tilt angles of a photovoltaic module using an experimental photovoltaic system," Environmental Progress \& Sustainable Energy, vol. 34, pp. 1156-1165, 2015.

[9] F. Rahmani, F. Razaghian, and A. Kashaninia, "High Power Two-Stage Class-AB/J Power Amplifier with High Gain and Efficiency," Journal of Academic and Applied Studies (JAAS), vol. 4, pp. 56-68, 2014.

[10] P. Dehghanian, S. Aslan, and P. Dehghanian, "Maintaining Electric System Safety through An Enhanced Network Resilience," IEEE Transactions on Industry Applications, 2018. 
[11] M. H. Imani, K. Yousefpour, M. J. Ghadi, and M. T. Andani, "Simultaneous presence of wind farm and V2G in security constrained unit commitment problem considering uncertainty of wind generation," in Texas Power and Energy Conference (TPEC), 2018 IEEE, 2018, pp. 1-6.

[12] S. Gharghabi and R. Safabakhsh, "Person recognition based on face and body information for domestic service robots," in Robotics and Mechatronics (ICROM), 2015 $3 r d$ RSI International Conference on, 2015, pp. 265-270.

[13] S. Gharghabi, B. Azari, F. Shamshirdar, and R. Safabakhsh, "Improving person recognition by weight adaptation of soft biometrics," in Computer and Knowledge Engineering (ICCKE), 2016 6th International Conference on, 2016, pp. 36-40.

[14] A. Khalili, R. Jha, and N. Jayakody, "Structural Health Monitoring of Skin-Stiffener Structures Using WSFEbased User Defined Elements in Abaqus," in 25th AIAA/AHS Adaptive Structures Conference, 2017, p. 1677.

[15] M. Montazeri, H. Pourgharibshahi, and M. Mohammadian, "Static voltage stability analysis of IRAN south-east power system using extended CPF method," in International Power system conference. Tehran-IRAN, 2012.

[16] S. Shahrokhabadi and M. Toufigh, "The solution of unconfined seepage problem using Natural Element Method (NEM) coupled with Genetic Algorithm (GA)," Applied Mathematical Modelling, vol. 37, pp. 27752786, 2013.

[17] S. Shahrokhabadi, V. Khoshfahm, and H. N. Rafsanjani, "Hybrid of natural element method (NEM) with genetic algorithm (GA) to find critical slip surface," Alexandria Engineering Journal, vol. 53, pp. 373-383, 2014.

[18] M. Khatibi, T. Amraee, H. Zargarzadeh, and M. Barzegaran, "Comparative analysis of dynamic model reduction with application in power systems," in Power Systems Conference (PSC), 2016 Clemson University, 2016, pp. 1-6.

[19] F. Rahmani and M. Barzegaran, "Dynamic wireless power charging of electric vehicles using optimal placement of transmitters," in Electromagnetic Field Computation (CEFC), 2016 IEEE Conference on, 2016, pp. 1-1.

[20] M. Ketabdar and A. Hamedi, "Intake Angle Optimization in 90-degree Converged Bends in the Presence of Floating Wooden Debris: Experimental Development," Florida Civ. Eng. J, vol. 2, pp. 22-27.2016, 2016.

[21] M. Khatibi, H. Zargarzadeh, and M. Barzegaran, "Power system dynamic model reduction by means of an iterative SVD-Krylov model reduction method," in Innovative Smart Grid Technologies Conference (ISGT), 2016 IEEE Power \& Energy Society, 2016, pp. 1-6.

[22] M. Ketabdar, "Numerical and Empirical Studies on the Hydraulic Conditions of 90 degree converged Bend with Intake," International Journal of Science and Engineering Applications, vol. 5, pp. 441-444, 2016.

[23] M. Ketabdar, A. K. Moghaddam, S. A. Ahmadian, P. Hoseini, and M. Pishdadakhgari, "Experimental Survey of Energy Dissipation in Nappe Flow Regime in Stepped Spillway Equipped with Inclined Steps and Sill," International Journal of Research and Engineering, vol. 4, pp. 161-165, 2017.

[24] S. H. Imani, S. Asghari, and M. Ameli, "Considering the load uncertainty for solving security constrained unit commitment problem in presence of plug-in electric vehicle," in Electrical Engineering (ICEE), 2014 22nd Iranian Conference on, 2014, pp. 725-732.

[25] E. Sadeghian, "Modeling and Checking the Power Quality of High Pressure Sodium Vapor Lamp," 2018.

[26] S. Hashemi, M. Montazeri, and M. Nasiri, "The compensation of actuator delay for hardware-in-the-loop simulation of a jet engine fuel control unit," Simulation, vol. 90, pp. 745-755, 2014.

[27] F. Rahmani, F. Razaghian, and A. Kashaninia, "Novel Approach to Design of a Class-EJ Power Amplifier Using High Power Technology," World Academy of Science, Engineering and Technology, International Journal of Electrical, Computer, Energetic, Electronic and Communication Engineering, vol. 9, pp. 541-546, 2015.

[28] T. Pourseif, M. T. Andani, Z. Ramezani, and M. Pourgholi, "Model Reference Adaptive Control for Robot Tracking Problem: Design \& Performance Analysis," International Journal of Control Science and Engineering, vol. 7, pp. 18-23, 2017.

[29] M. T. Andani, H. Pourgharibshahi, Z. Ramezani, and H. Zargarzadeh, "Controller design for voltage-source converter using LQG/LTR," in Texas Power and Energy Conference (TPEC), 2018 IEEE, 2018, pp. 1-6.

[30] A. Hamedi, M. Ketabdar, M. Fesharaki, and A. Mansoori, "Nappe Flow Regime Energy Loss in Stepped Chutes Equipped with Reverse Inclined Steps: Experimental Development," Florida Civil Engineering Journal, vol. 2, pp. 28-37, 2016.

[31] A. Rouholamini, H. Pourgharibshahi, R. Fadaeinedjad, and M. Abdolzadeh, "Temperature of a photovoltaic module under the influence of different environmental conditions-experimental investigation," International Journal of Ambient Energy, vol. 37, pp. 266-272, 2016.

[32] M. Baqersad, M. Mohammadafzali, B. Choubane, C. Holzschuher, A. Hamedi, and H. Ali, "Precision Assessment of the Florida Texture Meter in Hot Mix Asphalt," Journal of Transportation Engineering, Part B: Pavements, vol. 144, p. 04018003, 2018.

[33] M. T. Andani and Z. Ramezani, "Robust Control of a Spherical Mobile Robot," 2017

[34] M. Jafari, G. Atefi, and J. Khalesi, "Advances in nonlinear stress analysis of a steam cooled gas turbine blade," Latin American applied research, vol. 42, pp. 167-175, 2012.

[35] M. Hosseini Imani, M. Jabbari Ghadi, S. Shamshirband, and M. M. Balas, "Impact Evaluation of Electric Vehicle Parking on Solving Security-Constrained Unit Commitment Problem," Mathematical and Computational Applications, vol. 23, p. 13, 2018.

[36] B. Rahmani and S. R. Hashemi, "Internet-based control of FCU hardware-in-the-loop simulators," Simulation Modelling Practice and Theory, vol. 56, pp. 69-81, 2015.

[37] F. K. Purian and E. Sadeghian, "Mobile robots path planning using ant colony optimization and Fuzzy Logic algorithms in unknown dynamic environments," in Control, Automation, Robotics and Embedded Systems (CARE), 2013 International Conference On, 2013, pp. 16.

[38] S. Shahrokhabadi and A. Ahmadi, "Method of Fundamental Solution (MFS) coupled with Particle Swarm Optimization (PSO) to determine optimal phreatic line in unconned seepage problem," Scientia Iranica. Transaction A, Civil Engineering, vol. 20, p. 1327, 2013

[39] H. N. Rafsanjani, S. Shahrokhabadi, and A. Hadjahmadi, "The Use of Linear Regression to Estimate the Actual 
International Journal of Science and Engineering Applications

Volume 7-Issue 06, 71-79, 2018, ISSN:-2319-7560

Hourly Production of a Wheel-Type Loader in Construction Projects," in ICSDEC 2012: Developing the Frontier of Sustainable Design, Engineering, and Construction, ed, 2013, pp. 727-731.

[40] A. F. Bastani, Z. Ahmadi, and D. Damircheli, "A radial basis collocation method for pricing American options under regime-switching jump-diffusion models," Applied Numerical Mathematics, vol. 65, pp. 79-90, 2013.

[41] A. F. Bastani and D. Damircheli, "An adaptive algorithm for solving stochastic multi-point boundary value problems," Numerical Algorithms, vol. 74, pp. 11191143, 2017.

[42] A. Khalili, R. Jha, and D. Samaratunga, "Spectrally formulated user-defined element in conventional finite element environment for wave motion analysis in 2-D composite structures," European Journal of

Computational Mechanics, vol. 25, pp. 446-474, 2016.

[43] A. Khalili, D. Samaratunga, R. Jha, T. E. Lacy, and G. Srinivasan, "Wavelet spectral finite element based userdefined element in abaqus for modeling delamination in Composite Beams," in 23rd AIAA/AHS Adaptive Structures Conference, 2015, p. 1726.

[44] A. Khalili, R. Jha, and D. Samaratunga, "The Wavelet Spectral Finite Element-based user-defined element in Abaqus for wave propagation in one-dimensional composite structures," Simulation, vol. 93, pp. 397-408, 2017. 